- Improved parental/patient understanding of diabetes management:Promoting autonomy

- Improve quality of service by increasing efficiency and efficacy.

Methods Discussion in diabetes multidisciplinary team meeting. Process mapping of patient journey and ways to improve upload at home

Collected baseline data of number of patients/families uploading their metres and pumps at home in all three hospitals across the trust.

Multi-facetted approach was implemented to achieve our aim.

- Did home visits to understand the issue more closely.

- Preparation of flyers and leaflets to help parents open their Diasend account and link with the clinic.

- Contacted parent support groups and sent flyers and leaflets to parents via email.

- Encouraged team members to discuss the issue with the parents in clinic.

- Provided a Tablet for the clinic to open Diasend account and link with the clinic.

- Organised a family evening to run 2 Diasend workshops for the parents to open Diasend account and link with the clinic.

Result All three units recorded an increase in number of patients/parents uploading at home. Over the period of 6 months we recorded an increase from $8 \%$ to $30 \%, 35 \%$ to $47 \%$ and $41 \%$ to $62 \%$ respectively in diabetes clinics at Princess of Wales Hospital, Morriston Hospital, and Neath Port Talbot Hospital.

Conclusion Downloading at home:

- Enables more efficient use of clinic time and reduces waiting time in outpatient department.

- Has the potential to help improve the patient/parents understanding of diabetes management leading to improved clinical outcomes.

- Motivated healthcare professionals to discuss this issue on every contact.

\section{G372 RAPID CYCLE AUDIT - EMBEDDING MULTIDISCIPLINARY QUALITY IMPROVEMENT IN THE CHILDREN'S EMERGENCY DEPARTMENT}

DR James, D Hanna, S Milsom, W Christian. Children's Emergency Department, University Hospitals Bristol NHS Foundation Trust, Bristol, UK

\subsection{6/archdischild-2018-rcpch.362}

Aims Quality Improvement is central to the development of any successful department and individual involvement can lead to an increased sense of ownership and potentially improved morale. We set out to design a programme that would involve all members of the Children's Emergency Department (CED) team in measuring performance, designing innovation and monitoring change.

Methods 4 important targets were identified amongst the CED senior team: Pain management; Observation frequency; Sepsis screening and handover. An excel proforma was built allowing different team members to collect data on a rotating weekly basis using the 'Medway' computer system. The proforma auto-populated run charts to measure change which were then posted in a central space within the CED with key messages shared amongst the multidisciplinary team and discussed at handover.

Results Collection of data took place on $82 \%$ and $75 \%$ of potential weeks for pain management and observation frequency respectively over 10 months. Of the four initial projects the biggest improvement in care came in the recording of pain scoring at triage from $12 \%$ to $75 \%$ after introducing mandatory scoring at triage and using a 'pain sticker'. Observation frequency was more problematic with no improvement seen over the time despite increased education. Sepsis was abandoned as the small number of potential patients made the methodology unsuitable. Handover was swapped to safeguarding when local practice was reviewed and is ongoing.

Conclusion This work demonstrated success in embedding data measurement as part of the regular weekly timetable for the department. This first iteration however, failed to make significant improvements in the majority of areas studies and showed the need for both individual project ownership and also time for the team to meet and potentially co-design change. Going forward the programme has been adjusted to study one area for a month at a time with an individual champion for each project.

\section{G373 ABSTRACT WITHDRAWN}

\section{G374 IMPROVING THE QUALITY OF PAEDIATRIC PRESCRIBING ON A GENERAL PAEDIATRIC WARD}

K Raja, M Ocansey, Y Bonsu, C Benn, J Runnacles. Department of Paediatrcs, Royal Free Hospital NHS Foundation Trust, London, UK

\subsection{6/archdischild-2018-rcpch.363}

Aims Prescribing errors are the most common form of medication errors with potential to cause harm, especially in paediatrics. Majority of prescribing is done by junior doctors, some with little paediatric experience. Previous audits highlighted high incidence of errors but lost momentum following change in junior doctors.

The aim of our project was to measure inpatient prescription errors, identify the most common drug errors, and implement interventions to reduce these.

Methods An enthusiastic multidisciplinary team including doctors, pharmacists, nurses and physician's assistant (to provide continuity) used The Model for Improvement to test interventions according to errors noted.

The importance of the project was communicated to all paediatric trainees (by email/face to face teaching) and ward nursing staff. Safe prescribing sessions were emphasised during induction of different junior doctor groups.

Our ward pharmacist assessed all drug charts of inpatients for two days each week collecting data on error rate and drugs involved.

PDSA cycles from April 2017 tested versions of a weekly 'Druggle' where an observed drug error was highlighted by pharmacist to all members of the ward multidisciplinary team following ward safety huddles, with interactive 'Spot the Error' sessions.

A (P) outlining the Druggle was displayed in the doctors' office and emailed weekly to junior doctors with learning points/reminders. Junior doctors designed a prescribing checklist and requested anonymised pictures of errors on $(\mathrm{P}) \mathrm{s}$. 
Results There was an improvement in prescribing errors following introduction of Druggles in week 3 and a prescribing checklist in week 7, illustrated on annotated run charts for 20 weeks with 7 consecutive points below the median of $17.9 \%$. Incorrect prescribing of Ibuprofen was responsible for $58 \%$ of wrong dose calculations in the first 12 weeks. Interventions to improve this (dedicated Druggle, email to junior doctors, nurse education), resulted in a drop to $0 \%$ in the subsequent 7 weeks.

Conclusion Identification of common prescribing errors, weekly Druggles, and empowering nursing staff to identify errors have all contributed to improved prescribing. The project is ongoing, with plans to give individual feedback on errors along with shared learning, to broaden interventions to include other specialties, and to ensure the improvements are sustained.

\section{G375 GET SET FOR LABOUR WARD. OPTIMISING TEMPERATURE MANAGEMENT IN PRETERM INFANTS (<32 WEEKS GESTATION)}

${ }^{1}$ MI Duggan, ${ }^{1} \mathrm{C}$ Rennie, ${ }^{1} \mathrm{C}$ Nicholl, ${ }^{1} \mathrm{M}$ Brownell, ${ }^{2} \mathrm{~L}$ Sexton, ${ }^{1} \mathrm{~J}$ O'Shea, ${ }^{1} \mathrm{AM}$ Heuchan. ${ }^{1}$ Neonatal Unit, Royal Hospital for Children, NHS Greater Glasgow and Clyde, Glasgow, UK; ${ }^{2}$ University of Glasgow Medical School, University of Glasgow, Glasgow, UK

\subsection{6/archdischild-2018-rcpch.364}

Aim To design and implement a quality improvement project to optimise normothermia $\left(36.5^{\circ} \mathrm{C}-37.5^{\circ} \mathrm{C}\right)$ in preterm infants on admission to neonatal intensive care (NICU).

Methods A prospective audit of admission temperatures over a 12 month period from 01/01/2016 to 31/12/2016 revealed 25 $(31 \%)$ infants $<32$ weeks gestation were hypothermic on admission despite routine use of plastic bags and radiant heaters at delivery. A bundle of evidence based processes was compiled. These were based on NLS guidance of optimal environmental temperature, use of warmed mattresses, plastic wrapping, warmed incubators and warmed humidified gases. Also included was the American Academy of Paediatric guidance on the use continuous temperature monitoring at resuscitation. The bundle: 'Get Saturation Ecg Temperature for labour ward' was implemented following staff education, including advice on improving temperature if low on monitoring during stabilisation. A Lifestart trolley was used to deliver stabilisation with the cord intact for $60 \mathrm{~s}$ and monitoring was with Philips XDS monitors. Compliance with the number of process measures were recorded by questionnaire following each delivery and admission axillary temperature recorded.

Results Since implementation of Get SET in June 2017, 32 preterm infants $<32$ weeks have been admitted to NICU. 26 (81\%) were normothermic, 4 (13\%) were hypothermic and 2 (6\%) were hyperthermic. $75 \%$ of the hypothermic infants had an admission temperature $>36^{\circ} \mathrm{C}$ and no infant had an admission temperature $<35.9^{\circ} \mathrm{C}$ (table 1 ). Bundle compliance was not followed in 3 out of the 4 cases of hypothermic admissions, the remaining case was a prolonged breech delivery. Bundle compliance overall was $82 \%$.

Conclusion Quality improvement measures implemented to actively monitor and maintain temperatures in the normothermic range during stabilisation increased the proportion of preterm infants admitted with temperatures in the optimal range.

\begin{tabular}{lll}
$\begin{array}{l}\text { Abstract G375 Table } 1 \\
\text { implementation of Get SET }\end{array}$ & Hypothermic range before and after \\
\hline Temperature range & $\begin{array}{l}\text { Pre Get SET project } \\
\text { Number of babies }\end{array}$ & $\begin{array}{l}\text { Post Get SET project } \\
\text { Number of babies }\end{array}$ \\
\hline & $1(1 \%)$ & \\
$<35^{\circ} \mathrm{C}$ & $1(1 \%)$ & $0(0 \%)$ \\
$35.1^{\circ} \mathrm{C}-35.5^{\circ} \mathrm{C}$ & $7(9 \%)$ & $0(0 \%)$ \\
$35.6^{\circ} \mathrm{C}-36^{\circ} \mathrm{C}$ & $16(20 \%)$ & $1(3 \%)$ \\
$36.1^{\circ} \mathrm{C}-36.4^{\circ} \mathrm{C}$ & $3(9 \%)$ \\
\hline
\end{tabular}

\section{G376 REDUCING PRESCRIBING ERRORS: MAKING ELECTRONIC PRESCRIBING WORK FOR OUR CHILDREN WITH CYSTIC FIBROSIS, WITH MULTI-DISCIPLINE COLLABORATION}

${ }^{1} \mathrm{E}$ Vittery, ${ }^{2} \mathrm{E}$ Bayliss, ${ }^{1} \mathrm{M}$ Thomas, ${ }^{3} \mathrm{Y}$ Tse. ${ }^{1}$ Paediatric Respiratory Medicine, Great North Children's Hospital, Newcastle upon Tyne, UK; ${ }^{2}$ Pharmacy Directorate, Great North Children's Hospital, Newcastle upon Tyne, UK; ${ }^{3}$ Paediatric Nephrology, Great North Children's Hospital, Newcastle upon Tyne, UK

\subsection{6/archdischild-2018-rcpch.365}

Aims We noted a pattern of multiple prescribing errors for cystic fibrosis (CF) inpatients, a high-risk group where polypharmacy is unavoidable. Errors persisted despite the introduction of electronic prescribing (EP) in our Children's hospital in 2016, and a subsequent CF prescribing care set. EP is often seen by clinicians as a fixed unalterable system contributing to rather than ameliorating errors. We wanted to demonstrate increased use of the care set alongside an expected reduction in prescribing errors, through a process of multi-disciplinary quality improvement in liaison with EP programmers.

Methods We met monthly, process mapping how the team interacts with our EP system. Sequential Plan-Do-Study-Act cycles were carried out and functionality added and optimised so they were used reliably, including care sets, automatic admission notification and judicious pop-up alerts. The National Coordinating Council for Medication Error Reporting and Prevention score (NCC MERP) was used to categorise error severity (A-I).

Results In total, 20 patients (320 medication orders) were evaluated. The most common prescribing errors were: omission of a regular medicine (27\%), wrong formulation (19\%) and wrong dose (14\%). One third of prescriptions with error (s) were non-CF specific drugs that could not be prescribed using the care set. These errors would require different error reduction strategies to be tested and were excluded from further analysis.

Through our interventions, we demonstrated increased utilisation of the CF care set, from $42 \%$ to $70 \%$, alongside a reduction in prescriptions with $\geq 1$ error, from $43 \%$ to $27 \%$. The highest severity category seen in this study (D: errors that required intervention to preclude harm, or extra monitoring) was reduced from $27 \%$ to $15 \%$.

Conclusion It is important to recognise that clinical teams can significantly reduce medication errors, and their severity, by working closely with EP programmers to change and adapt EP functions, and evaluate their subsequent utilisation and efficacy. 